\title{
Impact of sepsis on the dynamics of diaphragmatic function in patients under mechanical ventilation
}

\author{
M Dres $^{1,2^{*}}$, BP Dubé ${ }^{2}$, L Dangers ${ }^{1,2}$, J Mayaux ${ }^{1}$, T Similowski ${ }^{1,2}$, A Demoule ${ }^{1,2}$ \\ From ESICM LIVES 2015 \\ Berlin, Germany. 3-7 October 2015
}

\section{Introduction}

Sepsis and mechanical ventilation are both risk factors of diaphragmatic dysfunction (DD) in critically ill patients. The evolution of diaphragmatic function under mechanical ventilation in septic and non-septic patients has not been described.

\section{Objectives}

To assess the evolution of diaphragmatic function in patients under mechanical ventilation (MV) with and without sepsis on admission.

\section{Methods}

We prospectively included mechanically ventilated patients of a 16-beds medical intensive care unit. Diaphragmatic function was estimated by the gold standard method using bilateral anterior magnetic stimulation (Ptr,stim) at two distinct time points:

1) during the first 24 hours of mechanical ventilation and

2) in the 24 hours after switching to spontaneous ventilation mode. Sepsis was defined according to the Surviving Sepsis Campaign criteria. A Ptr,stim lower than -11 $\mathrm{cmH}_{2} \mathrm{O}$ defined DD.

\section{Results}

Forty-two critically ill patients were investigated (26 males, mean age $61 \pm 14$ years, SOFA score $9 \pm 4$ ). Twenty six (62\%) had sepsis on admission. Patients with and without sepsis were similar with regards to age, gender, past medical conditions, length of stay and of MV, use of sedatives and SOFA score). The first and second evaluations were respectively performed after a median (interquartile range) of 1(1-1) and 3.75 (2-5) days from the onset of MV. Overall, DD was present in 34 patients $(81 \%)$ on the first evaluation and in $35(83 \%)$ on the second. Initial Ptr,stim was lower in patients with sepsis $\left(6.6 \pm 3.2\right.$ vs $\left.9.7 \pm 4.8 \mathrm{cmH}_{2} \mathrm{O}, \mathrm{p}=0.016\right)$. Patients with initial sepsis had a mean increase of $29.7 \%$ in Ptr,stim between the two evaluations, whereas in patients without initial sepsis Ptr,stim decreased by a mean $10.9 \%(\mathrm{p}=0.03)$. On average, Ptr,stim increased by 12.4 percent.day ${ }^{-1}$ and decreased by 3.8 percent.day $^{-1}$ in septic and non septic patients, respectively.

\section{Conclusions}

In critically ill patients, sepsis on admission is associated with worse but partially reversible diaphragmatic dysfunction. On the opposite, patients without sepsis had a continuous decrease in diaphragm function. These findings provide new insight in the interrelated contributions of the sepsis and MV on diaphragmatic dysfunction.

\section{Grant Acknowledgment}

Martin DRES was supported by Assistance Publique Hôpitaux de Paris

\section{Authors' details}

${ }^{1}$ Hopital Pitie Salpetriere, Assistance Publique Hôpitaux de Paris, Respiratory and Critical Care Department, Paris, France. ${ }^{2}$ Sorbonne Universités, UPMC Université Paris 06, INSERM, UMRS1158 Neurophysiologie Respiratoire Expérimentale et Clinique, Paris, France.

Published: 1 October 2015

\section{doi:10.1186/2197-425X-3-S1-A94}

Cite this article as: Dres et al:: Impact of sepsis on the dynamics of diaphragmatic function in patients under mechanical ventilation. Intensive Care Medicine Experimental 2015 3(Suppl 1):A94. 